\title{
The Evolution of \\ Automotive Technology: A Handbook
}




\title{
Other SAE books of interest
}

\author{
Chrysler Engines 1922-1998 \\ By Willem L. Weertman \\ (Product Code: R-365)
Hall-Scott: The Untold Story of a Great American Engine Maker
By Ric A. Dias and Francis H. Bradford
(Product Code: R-368)
World History of the Automobile
By Erik Eckermann
(Product Code: R-272)

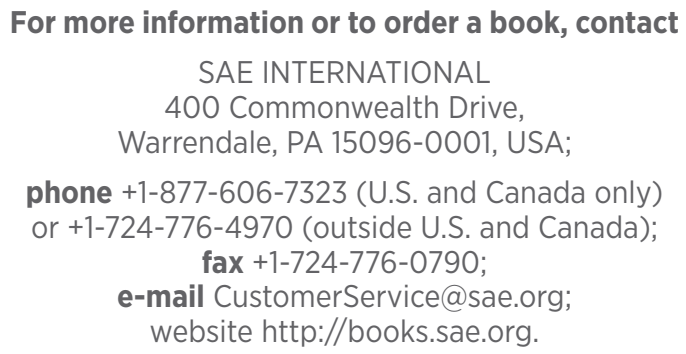




\title{
The Evolution of Automotive Technology: A Handbook
}

\author{
By Gijs Mom
}

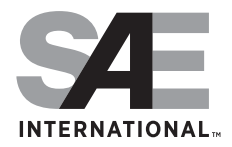




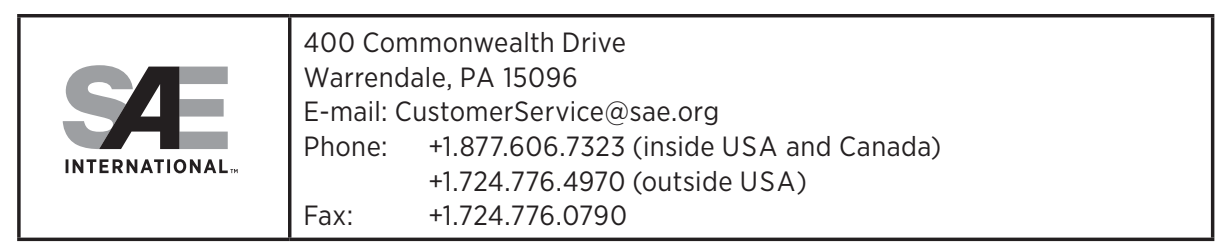

Copyright (C) 2014 SAE International. All rights reserved.

No part of this publication may be reproduced, stored in a retrieval system, distributed, or transmitted, in any form or by any means without the prior written permission of SAE International. For permission and licensing requests, contact SAE Permissions, 400 Commonwealth Drive, Warrendale, PA 15096-0001 USA; e-mail: copyright@sae.org; phone: +1-724-772-4028; fax: +1-724-772-9765.

\section{SAE Order Number R-435 DOI 10.4271/R-435}

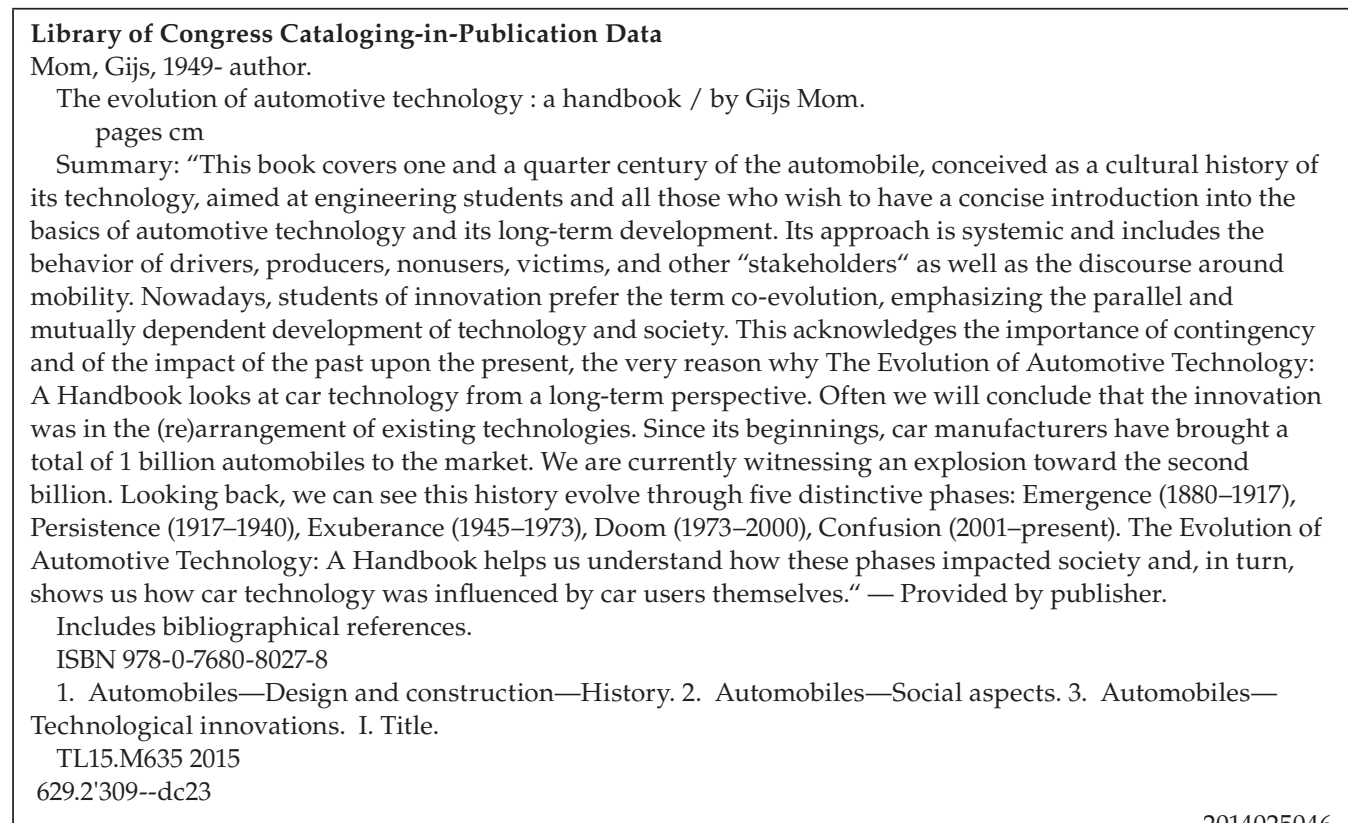

Information contained in this work has been obtained by SAE International from sources believed to be reliable. However, neither SAE International nor its authors guarantee the accuracy or completeness of any information published herein and neither SAE International nor its authors shall be responsible for any errors, omissions, or damages arising out of use of this information. This work is published with the understanding that SAE International and its authors are supplying information, but are not attempting to render engineering or other professional services. If such services are required, the assistance of an appropriate professional should be sought.

\section{ISBN-Print 978-0-7680-8027-8 ISBN-epub 978-0-7680-8147-3 \\ ISBN-PDF 978-0-7680-8145-9 ISBN-prc 978-0-7680-8146-6}

To purchase bulk quantities, please contact:

SAE Customer Service

E-mail: CustomerService@sae.org

Phone: +1-877-606-7323 (inside USA and Canada)

+1-724-776-4970 (outside USA)

Fax: $\quad+1-724-776-0790$

Visit the SAE International Bookstore 
to Maarten, and his great-grandfather 


\section{Contents}

Preface ...............................................................................................iii

\section{Chapter 1 - The Evolution of Automotive Technology ................ 1}

1.1 Introduction: Why This Book, and How? .....................................................

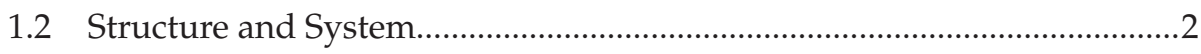

1.3 A Quasi-Evolutionary Approach ..................................................................

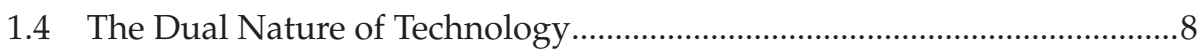

1.5 One and a Quarter Century of Cars ..........................................................12

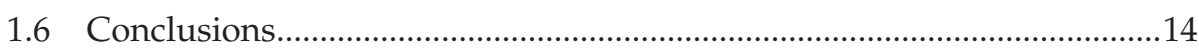

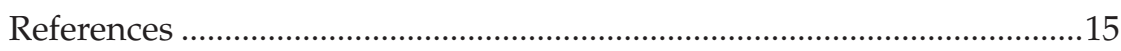

PART I: STRUCTURE .............................................................. 19

Chapter 2 - The Engine: Mixture Formation ............................ 21

2.1 Introduction: Finding the Car's Basic Layout ...........................................21

2.2 Constructing a Taxonomy of Engines …...................................................23

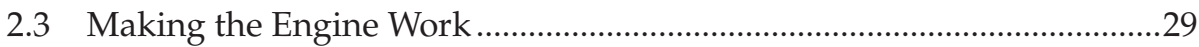

2.4 Carburation: Constructing the Mixture ......................................................33

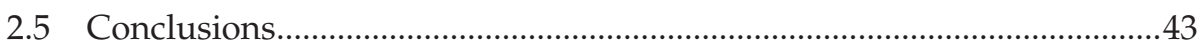

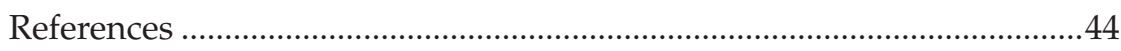

Chapter 3 - The Engine: Ignition ................................................ 47

3.1 Introduction: Regulating the Engine from Its Industrial

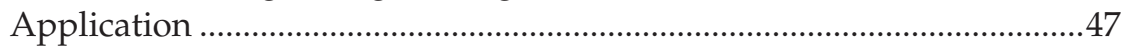

3.2 Robert Bosch and the Magneto Ignition ..................................................50

3.3 Charles Kettering and the Systemic Approach of Technical Problems......55

3.4 Struggle of the Systems: Constructing Both a Winner and His Story........59 


\section{Chapter 4 - The Drivetrain: How to Get the Energy from} the Engine to the Wheels

4.1 Introduction: Shaping the Drivetrain Configuration................................69

4.2 From Belts and Chains to Prop Shafts (and Belts and Chains) ................72

4.3 The Clutch: Substitution and Coexistence ..................................................75

4.4 The Final Drive: A Feast of Gearwheel Designs .......................................81

4.5 Universal Joints, Front-Wheel Drive, and the Reconfiguration

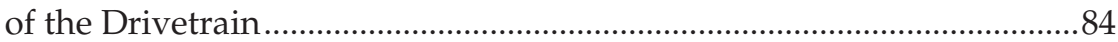

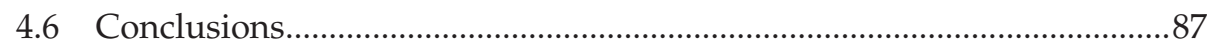

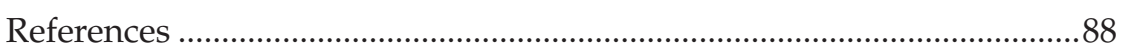

\section{Chapter 5 - The Drivetrain: Multiplying Energy,}

De-Multiplying Speed..............................................................91

5.1 Introduction: Costs and Cheapness …….....................................................91

5.2 The Transmission: How to Circumvent Gear Shifting .............................92

5.3 The Automatic Transmission: Diverging Car Cultures................................ 99

5.4 Transmission Manufacturers and Automotive Production .....................103

5.5 Conclusions: Expectations and the Distant User ....................................107

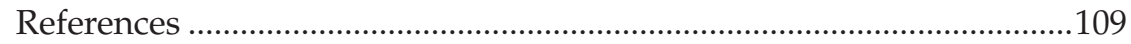

\section{Chapter 6 - The Chassis: Getting Around the Corner....................111}

6.1 Introduction: Pre-Car Developments....................................................... 111

6.2 Constructing the Automotive Chassis ...................................................... 115

6.3 Steering: Keep It Simple, Be Precise ..................................................... 117

6.4 Steering the Car, Theorizing Dynamic Behavior.....................................121

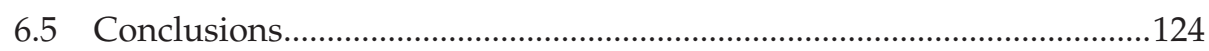

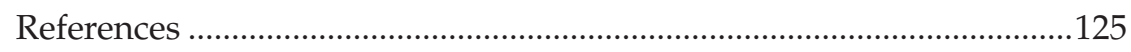

\section{Chapter 7 - Wheel Suspension: Who Will Absorb}

the Shocks?.......................................................................... 127

7.1 Introduction: The Suspension as System...............................................127

7.2 How to Guide the Wheels? Big Problems, Many Solutions ....................130

7.3 Who Should Absorb the Shocks? Defining the Role of Tires...................137 
7.4 Conclusions

References

\section{Chapter 8 - Stopping the Car: How to Generate and} Distribute Braking Energy

8.1 Introduction: Braking Levels Within the Car Structure

8.2 The Braking System: How to Distribute Braking Energy over the Wheels

8.3 Drums and Discs: Substitution and Coexistence 158

8.4 Conclusions 163 References

PART II: SYSTEM 169

\section{Chapter 9 - Automation: Driver Deskilling and the} "Electronic Revolution".

9.1 Introduction: Trends in Automotive Technology ..................................171

9.2 Postwar Automation, an Electronic Revolution? ...................................176

9.3 The Lay Motorist and the Navigation Revolution ..................................184

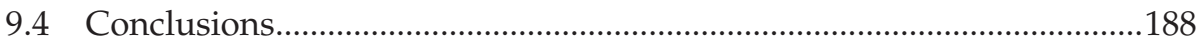

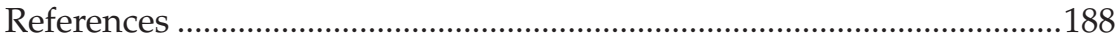

\section{Chapter 10 - Safety: From Shell to Capsule to Cocoon,} from Danger to Risk .............................................................. 191

10.1 Introduction: Closing the Automotive Body

10.2 "Control the Lunatic!" The Hunt for the "Accident-Prone"

Motorist 193

10.3 Protecting the Motorists: Active and Passive Safety ...............................200

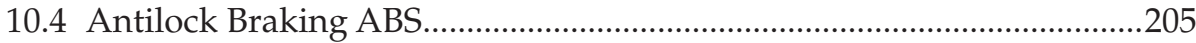

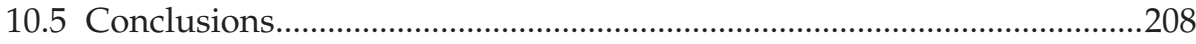

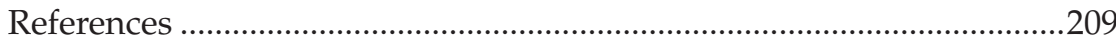

Chapter 11 - Environment: Discovering the Other ...................213

11.1 Introduction: Inventing the Environment ..............................................213

11.2 Engineering Car Noise While Closing the Body: Liberating Vision from Sensual Interference 
11.3 The Diesel Car as Remedy: Car Cultures and the Perception of

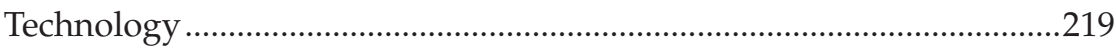

11.4 Lean-Burn versus Catalyst: The Struggle for a Clean Car .......................226

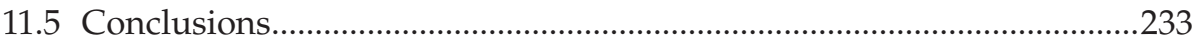

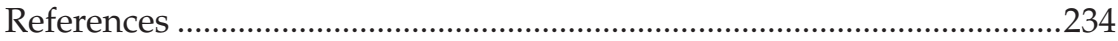

\section{Chapter 12 - Scientification: The Co-evolution of}

Engineering Knowledge ........................................................ 239

12.1 Introduction: How Do Engineers Know? ..............................................239

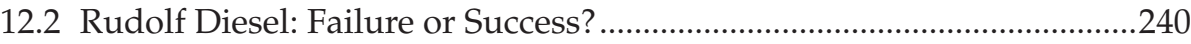

12.3 Team Work in Laboratories: Scientification of Car Dynamics.................244

12.4 Constructing the State of the Art: Conferences, Education,

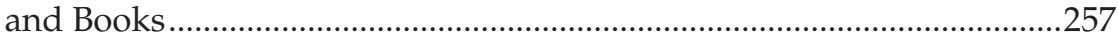

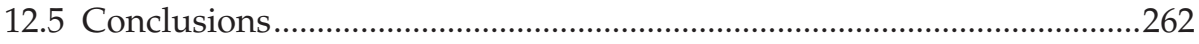

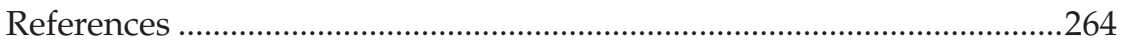

\section{Chapter 13 - Decarbonization: Searching for Radical} Alternatives ............................................................................. 269

13.1 Introduction: The Importance of Expectations ..........................................269

13.2 The End of Oil! In the Early 1920s! ...........................................................2.

13.3 The Promise of the Electric Vehicle: A Perpetual Car of

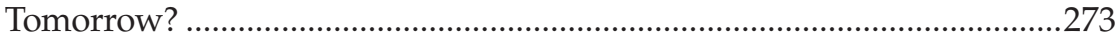

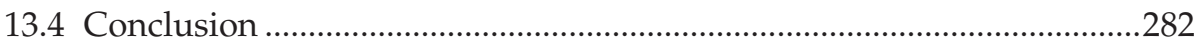

References ..................................................................................28

Chapter 14 - Innovation: Production, Diffusion, Use ............. 287

14.1 Introduction: How to Construct Trends? ................................................287

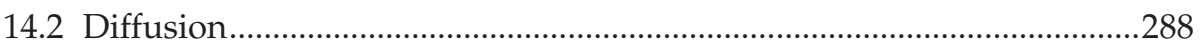

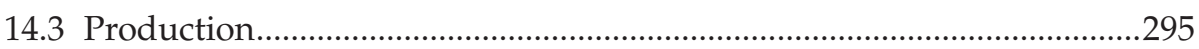

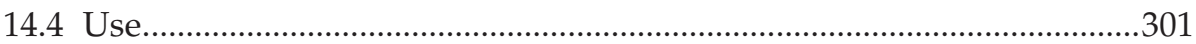

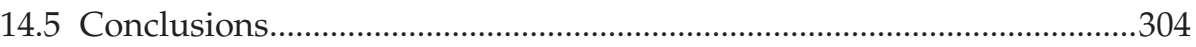

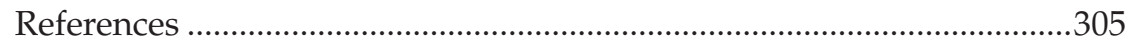

Chapter 15 - World Mobility: Shifting the Focus ................... 307

15.1 Introduction: The West and the Rest.....................................................307

15.2 Road versus Rail: Clashing Mobility Cultures ........................................308 
15.3 Global Urban Mobility: The Case of the Rickshaw. 311

15.4 Conclusion: The Rest and the West 316 References 320

Chapter 16 - Conclusions 323

References .332

Bibliography. 333

Index 357

About the Author 


\section{Preface}

The Evolution of Automotive Technology: A Handbook is a quarter century-old dream come true.

Back in the 1980s, a Dutch publisher asked me to become the editor of a three-volume technical handbook conceived in the 1920s, by George Frederik Steinbuch, one of the pioneers of Dutch automotive engineering. I had just graduated from HTS Autotechniek (HTS standing for Hogere Technische School, or Polytechnic, focusing on Automotive Technology), and had also finished a Master's degree in literary history. Ambitiously, I proposed a ten-volume successor instead. Although this plan got stranded between the busyness of my subsequent career as a lecturer at the Polytechnic, and multiple reorganizations of the publishing house, five volumes were eventually finalized, with three of them translated into German. For every volume, I studied the history of the topic and wrote two introductory chapters myself (on history and basic theory), while editing the contributions of the experts in the remainder of each volume.

At the end of the 1990s, I received a PhD in history of technology, and transferred to Eindhoven University of Technology (TU/e) to take up a position in research and teaching, focusing on mobility research, traffic engineering, and the automotive culture.

Coincidentally, some years ago, the great-grandson of George Frederik Steinbuch, TU/e Mechanical Engineering professor Maarten Steinbuch, asked me if I would like to help set up a new Master's program in automotive technology. In addition, the board of the university decided to attract a new, more socially oriented type of engineering students by offering a brand-new Bachelor of Automotive Technology program at the Electrical Engineering Department, prioritizing the study of control and systems engineering, the electric and hybrid propulsion as well as the smart car. My answer should not be difficult to guess.

Suddenly, car technology proper, a closed book to many students of the history of the automobile, came alive again for me. I started to dig into my own history, combining this with the new educational and theoretical insights I had gathered during the last decade or so. The result is the book before you, tested extensively during the first three years of the Bachelor's program, and far more years at the Master's level. My audience was a continuously changing international group of students, whom I would like to 
thank here for helping me put the content to the test. Some of them produced reports that made it into the pages of this book.

Of these students, some have to be mentioned by name: student assistants Jorrit Bakker, Valerian Meijering and, especially, Wilco Pesselse and Texas van Leeuwenstein. They helped set up the courses, gather and scan illustrative material, develop the quiz questions, and go through numerous versions of texts, with their source references and requests for permission to use illustrations.

I thank Bart Smolders, Director of Education of the Electrical Engineering Department, who made the initial investment into the student assistant support; Johan Schot, Director of the Technology in Society group of the IE\&IS Department for following up in the final phase, as well as Jos Hermus, Managing Director of the same department, for providing the basis for the continuation of this project beyond my retirement.

I was also able to make prolific use of the Netherlands Center for Automotive Documentation (NCAD), which I had co-founded at the end of the 1990s, and which keeps several thousands of printed material, including my own collection of old handbooks, as well as my complete set of all Steinbuch editions since 1922.

I would like to thank director Jan Wouters, the many NCAD volunteers who helped search for illustrations as well as its board of directors, chaired by Peter van der Koogh, for their cooperation during the past years.

I also would like to thank Jan Schukking, long-since retired from Kluwer Technische Boeken BV, who hired me in the 1980s as an editor of "the Steinbuch series", and who never lost his confidence in me. I am very pleased that I can show him the results of his confidence in the form of this book. I am also grateful to the current copyright holder of the Steinbuch series, mybusinessmedia, and to intermediary Henk Heuvelman, for granting me permission to use many of the original illustrations. The same gratitude extends to the many copyright holders of the other illustrations necessary in a handbook like this: they are duly credited in the caption of the figures. Every effort has been made to identify and contact copyright holders of illustrations. The author requests notification of any corrections that should be incorporated in future editions.

The preparation of the printed book was crucially advanced by Georgine Clarsen (Wollongong University), Ann Johnson (University of South Carolina), and Lee Vinsel (Stevens Institute of Technology), who read earlier versions of the manuscript, and acted as reviewers. I also thank the anonymous reviewer, who reminded me of the differences in language and study style between engineering students and other types of students. I hope that his influence on the writing style of this text will convince other teachers and professors, who are giving courses in automotive engineering, to make use of this book in their classes. It is also my hope that engineers and others interested in the long-term development of the car will find this book educational and fun to read. 
My thanks also go to the staff at SAE International for guiding me through the labyrinth of book production: Martha Swiss and Monica Nogueira.

Finally, I would like to acknowledge the breadth of vision of Maarten Steinbuch, who, supported by many colleagues at TU/e, made this project possible in the first place. In less than a decade, automotive technology and "smart mobility" have been made into one of the strategic areas of the university, quite a feat after a long period of automotive lull at this institution. I was very lucky to help shape this program during the last phase of my professional career.

I dedicate this book to Maarten, and his great-grandfather. They stand at the beginning and the end of my version of automotive technology history.

Gijs Mom

Shanghai, 18 August 2014 